\title{
Increased levels of proinflammatory cytokines and nitric oxide metabolites in neuropsychiatric lupus erythematosus
}

E Svenungsson, M Andersson, L Brundin, R van Vollenhoven, M Khademi, A Tarkowski, D Greitz, M Dahlström, I Lundberg, L Klareskog, T Olsson

Abstract:

Objective-To investigate systemic and intrathecal production of proinflammatory cytokines in relation to cerebrospinal fluid (CSF) nitric oxide (NO) release in patients with neuropsychiatric lupus erythematosus (NPLE)

Methods-Thirty patients with NPLE rated as mild, moderate, or severe were studied and CSF was obtained from 21 of these. Cytokine mRNA expressing cells were detected by in situ hybridisation. Soluble cytokines were assessed by enzyme linked immunosorbent assay (ELISA). Nitrite and nitrate were determined by capillary electrophoresis.

Department of Medicine,

Rheumatology Unit, Karolinska Hospital, Stockholm, Swe $\mathrm{R}$ van Vollenhoven I Lundberg L Klareskog

Department of Neurology, Karolinska Hospital $M$ Andersson L Brundin T Olsson

Department of Medicine, Neuroimmunology Unit, Karolinska Hospital M Andersson M Khademi M Dahlström

Department of Rheumatology Sahlgrenska University Hospital, Gothenburg, Sweden

A Tarkows

MR Research Centre, Department of Neuroradiology, Karolinska Hospital D Greitz

Correspondence to: Dr E Svenungsso Department of Rheumatology, Karolinska Hospital, S-171 76 Elisabet.Svenungsson $a$ medks.ki.se

Accepted 11 August 2000 College of Rheumatology (ACR) standardised nomenclature system facilitate further studies on NPLE. ${ }^{3}$
Explanations for neurological manifestations in SLE include damage to the nervous system mediated by autoantibodies and immune complexes. ${ }^{45}$ There is also evidence that vascular lesions in patients with SLE, both cerebral and others, are associated with the occurrence of antiphospholipid antibodies. ${ }^{6}$ Thus several recent studies have divided patients with NPLE into two groups, one consisting of patients with focal vascular lesions and antiphospholipid antibodies, and the other of patients with diffuse neurological symptoms without antiphospholipid antibodies. ${ }^{78}$ However, there is a significant overlap between these two groups, with an overrepresentation of antiphospholipid antibody positivity among patients with diffuse NPLE as well. Furthermore, there is evidence that antiphospholipid antibodies in NPLE may have other pathogenetic roles besides being thrombogenic. ${ }^{9} 10$

Another possible pathophysiological mechanism in NPLE is related to the direct or indirect effects of inflammatory mediators on the nervous system. Proinflammatory cytokines produced both outside and inside the central nervous system are known to have dramatic effects on the nervous system, perhaps best described in infections ${ }^{11}$ but local production of cytokines has also been shown to be of importance in primary aseptic neuroinflammatory diseases. ${ }^{12}$ Earlier studies have reported increased levels of interleukin 1 (IL1), interleukin 6 (IL6), and interferon $\alpha$ (IFN $\gamma$ ) in the cerebrospinal cereb NPLE ${ }^{13-15}$ Although free cytokines can be measured in body fluids, the results may be deceptive because cytokines have short half lives and are often bound to circulating receptors. Studies of cellular production may better reflect the in vivo activity of a particular cytokine ${ }^{12}$ We therefore analysed the number of mRNA expressing cells for selected cytokines in blood and CSF as well as soluble levels of cytokines in the CSF.

Nitric oxide (NO) is an important inflammatory mediator with a potential role in NPLE. has a short half life and is usually measured by its more stable oxidation products nitrite and nitrate. We recently reported that a small group of patients with NPLE had high levels of NO metabolites in the CSF. ${ }^{16}$ Cytokines such as tumour necrosis factor $\alpha(\mathrm{TNF} \alpha)$ and IFN $\gamma$ are potent inducers of inducible nitric oxide synthase (iNOS) in cerebral cell types, including human astrocytes, and may thus trigge 
Table 1 Patient characteristics at the time of inclusion (blank spaces indicate negative findings)

\begin{tabular}{|c|c|c|c|c|c|c|c|c|c|c|c|}
\hline $\begin{array}{l}\text { Patient } \\
\text { number }\end{array}$ & Age & $\begin{array}{l}\text { SLE } \\
\text { duration }\end{array}$ & $\begin{array}{l}\text { Anti-DNA } \\
\text { antibodies }\end{array}$ & $a P L^{\star}$ & $\begin{array}{l}\text { White matter } \\
\text { lesions }\end{array}$ & $\begin{array}{l}\text { Cerebral } \\
\text { infarction }\end{array}$ & $\begin{array}{l}\text { Cortical } \\
\text { atrophy* }\end{array}$ & $\begin{array}{l}\text { Disease } \\
\text { severity }\end{array}$ & $\begin{array}{l}\text { Currently active CNS } \\
\text { manifestation* }\end{array}$ & $S L E D A I$ & $\begin{array}{l}\text { Prednisolone } \\
\text { (mg/day) }\end{array}$ \\
\hline 1 & 50 & 4 & $1 / 100$ & + & & & & 3 & Dementia, seizures, & 26 & 0 \\
\hline 2 & 47 & 13 & & + & & Yes & & 1 & Fatigue, depression & 8 & 5 \\
\hline 3 & 23 & 1 & & + & & & & 1 & Fatigue, Cogn & 0 & 0 \\
\hline 4 & 49 & 10 & & + & ND & & & 1 & Vertigo, fatigue & 4 & 15 \\
\hline 5 & 61 & 12 & & & ++ & & & 3 & Psychosis, seizures & 20 & 40 \\
\hline 6 & 45 & 14 & & + & & & & 2 & Cogn, $\mathrm{Ha}$ & 8 & 5 \\
\hline 7 & 39 & 13 & & & & & ++ & 2 & Cogn, seizures & 16 & \\
\hline 8 & 57 & 21 & $1 / 100$ & + & ++ & Yes & + & 3 & OBS, seizures & 16 & 7.5 \\
\hline 9 & 51 & 2 & $1 / 400$ & + & & & & 3 & Psychosis, Cogn & 16 & 20 \\
\hline 10 & 49 & 1 & $1 / 3200$ & + & + & & + & 1 & $\mathrm{Ha}$, anxiety & 25 & 40 \\
\hline 11 & 47 & 1 & & + & & & & 1 & $\mathrm{Ha}, \mathrm{Cogn}$ & 8 & 0 \\
\hline 12 & 22 & 6 & $1 / 25$ & + & & & & 2 & OBS & 20 & 0 \\
\hline 13 & 37 & 22 & $1 / 3200$ & + & & & & 1 & $\mathrm{Ha}$, fatigue & 6 & 10 \\
\hline 14 & 56 & 12 & & + & ++ & & & 2 & Seizures, $\operatorname{Cogn}$ & 20 & 0 \\
\hline 15 & 58 & 27 & $1 / 1600$ & + & & & ++ & 2 & Seizures & 13 & 20 \\
\hline 16 & 74 & 2 & & + & ++ & & ++ & 2 & Seizures, $\mathrm{Ha}$ & 17 & 20 \\
\hline 17 & 26 & 1 & $1 / 100$ & + & & & & 1 & Cogn, Ha & 14 & 15 \\
\hline 18 & 42 & 27 & $1 / 100$ & + & ++ & & & 3 & OBS, PN, Ha & 18 & 0 \\
\hline 19 & 50 & 2 & $1 / 10$ & & ++ & & & 2 & Cogn, fatigue & 8 & 0 \\
\hline 20 & 55 & 2 & & & & & & 2 & Seizures & 12 & 0 \\
\hline 21 & 20 & 1 & & & & & & 1 & Cogn, $\mathrm{Ha}$ & 1 & 5 \\
\hline 22 & 52 & 19 & $1 / 25$ & + & + & Yes & & 2 & & 13 & \\
\hline 23 & 63 & 2 & & & & Yes & ++ & 2 & OBS, $\mathrm{Ha}$ & 8 & 3.75 \\
\hline 24 & 67 & 54 & & + & ND & & + & 2 & OBS, Ha & 9 & 0 \\
\hline 25 & 50 & 22 & & + & & & & 1 & Cogn & 8 & \\
\hline 26 & 34 & 4 & & - & & & & 1 & $\mathrm{Ha}$ & 12 & 7.5 \\
\hline 27 & 52 & 24 & & + & ++ & Yes & + & 3 & OBS, seizures & 26 & 17.5 \\
\hline 28 & 38 & 3 & & & + & & & 1 & Cogn, Ha & 10 & 0 \\
\hline 29 & 25 & 2 & & - & & & & 1 & Fatigue, $\mathrm{Ha}$ & 14 & 0 \\
\hline 30 & 38 & 21 & & + & + & Yes & & 3 & Myelopathy, $\mathrm{Ha}$ & 8 & 30 \\
\hline
\end{tabular}

aPL $=$ antiphospholipid antibodies: $+=$ present as either IgG cardiolipin antibodies, IgM cardiolipin antibodies or positive lupus anticoagulant test; white matte lesions (WML) on MRI: $+=$ moderate changes 4-10 WML, $++=$ severe changes 11-30 WML, ND $=$ MRI not done, only computed tomography performed; cor and had occurred within 10 days before inclusion: Cogn = subjective complaint of cognitive dysfunction, OBS = organic brain syndrome; $\mathrm{Ha}=$ severe headache; PN $=$ peripheral neuropathy.

within the central nervous system. ${ }^{18}$ Therefore we measured the levels of CSF NO metabolites in an extended group of patients with NPLE and determined correlations between CSF NO metabolites, soluble cytokine levels, and the number of cytokine mRNA expressing cells in blood and CSF. We also investigated whether the severity of neurological symptoms in patients with NPLE corresponded with CSF NO levels or with production of proinflammatory cytokines in blood or CSF.

\section{Patients and methods}

PATIENT GROUP

During 1996 and 1997 patients with SLE at the rheumatology unit, Karolinska Hospital in Stockholm Sweden, were examined and interviewed for neurological symptoms. Thirty patients with signs of NPLE were included (25 outpatient, five inpatients). Table 1 gives the patients' characteristics. The patients were all patients' characteristics. The patients were all
women, aged 20-74 years (mean (SD) 46 (13)). All patients fulfilled four or more of the 1982) ACR revised criteria for SLE. ${ }^{19}$ Patients with explanations for the neuropsychiatric symptoms other than SLE or the antiphospholipid syndrome were excluded. All patients were examined at inclusion by both a rheumatologist (ES) and a neurologist (MA). The local ethics committee approved the study.

SLE disease activity was measured using the SLE disease activity was measured using the
SLE Disease Activity Index (SLEDAI). ${ }^{20}$ To assess neurological SLE involvement, the patients' NPLE was scored at inclusion jointly by the rheumatologist and the neurologist after discussing each case as mild (patients who only reported subjective symptoms such as mild cognitive impairment but able to work, mood/ anxiety syndromes, lupus headache, fatigue), moderate (cognitive impairment unable to work, organic brain syndrome as defined by SLEDAI, ${ }^{20}$ epileptic seizures, one focal neurological symptom), or severe (psychoses, dementia, combinations of several neuropsychiatric symptoms). Formal neuropsychiatric assessment was made when clinically indicated. Smaller cerebrovascular lesions were in resonance imag un resonan ce imaging (MRI) after inclusion in the study, but this did not change our clinical ratings. Patients were included before the ACR case definitions for neuropsychiatric syndromes in systemic lupus erythematosus were published. ${ }^{3}$ Retrospectively, we have reassessed the patients' clinical data according to this nomenclature system. Twenty one of the 30 patients with clinical signs of NPLE were subected to lumbar puncture. Patients were excluded from lumbar puncture for the following reasons: receiving warfarin treatment $(n=2)$, platelet count $<100 \times 10^{9}(n=2)$, permasubjected to the procedure $(n=3)$, or technical difficulty ("dry tap", n=1).

Paired serum and CSF samples were obtained at inclusion and stored at $-20^{\circ} \mathrm{C}$. Serum levels of anti-dsDNA, anticardiolipin antibodies, and lupus anticoagulant were determined in the clinical laboratory at this institute. AntidsDNA antibodies were determined by immunofluorescence using a Crithidia luciliae kinetoplast assay. Anticardiolipin antibodies were measured by enzyme linked immunosorbent assay (ELISA) using ethanol fixed cardiolidish peroxidase conju- 
Table 2 Comparison between SLEDAI score and doctors' assessment of neuropsychiatric lupus erythematosus. Results are given as median (range)

\begin{tabular}{llrr}
\hline SLEDAI score & Mild & Moderate & \multicolumn{1}{l}{ Severe } \\
\hline Total SLEDAI score & $8(0-25)$ & $12(8-20)$ & $18(8-26)$ \\
Neurological SLEDAI score & $8(0-8)$ & $8(0-16)$ & $16(8-24)$ \\
Systemic (non-neurological) SLEDAI score & $2(0-17)$ & $0(0-13)$ & $2(0-18)$ \\
\hline
\end{tabular}

Table 3 Patients' neuropsychological symptoms, according to 1999 ACR case definitions for neuropsychiatric lupus erythematosus

\begin{tabular}{ll}
\hline $\begin{array}{l}\text { Patient } \\
\text { number }\end{array}$ & Neuropsychiatric syndromes as defined by the ACR \\
\hline 1 & Acute confusional state, cognitive dysfunction, seizure disorder, headache NOS \\
2 & Cerebrovascular disease, mood disorder \\
3 & Cognitive dysfunction, not tested according to criteria for ACR classification \\
4 & Cognitive dysfunction, not tested according to criteria for ACR classification \\
5 & Pyschosis, seizure disorder \\
6 & Cognitive dysfunction, headache NOS \\
7 & Cognitive dysfunction, seizure disorder \\
8 & Acute confusional state, seizure disorder, cerebrovascular disease \\
9 & Psychosis, cognitive dysfunction \\
10 & Headache NOS \\
11 & Lupus headache, cognitive dysfunction \\
13 & Acute confusional state, cognitive dysfunction \\
14 & Headache NOS \\
15 & Seizure disorder, cognitive dysfunction \\
16 & Seizure disorder \\
17 & Sizure disorder, headache NOS \\
18 & Cognitive dysfunction \\
19 & Polyneuropathy \\
20 & Acute confusional state \\
21 & Seizure disorder \\
22 & Acute confusional state \\
23 & Cerebrovascular disease, headache NOS \\
24 & Acute confusional state, headache NOS \\
25 & Acute confusional state, headache NOS \\
26 & Cognitive dysfunction \\
27 & Headache NOS \\
28 & Cerebrovascular disease, acute confusional state, seizure disorder, headache NOS \\
29 & Cognitive dysfunction, headache NOS \\
30 & Headache NOS \\
\hline
\end{tabular}

against human $\operatorname{IgG}$, respectively $\operatorname{IgM}$ (Dako). Lupus anticoagulant was determined using a modified dilute Russel viper venom method, (Biopool, Umea, Sweden) using Bioclot lupus anticoagulant.

MRI INVESTIGATION

MRI was performed on 28 patients, computed tomography (CT) on two. The MR examinations were performed on a $1.5 \mathrm{~T}$ MRI unit (Signa, GE medical systems, Milwaukee, WI) The patients were examined in the transaxial plane using a slice thickness of $5 \mathrm{~mm}$ and a slice gap of $2 \mathrm{~mm}$. Imaging included conventional fast spin echo $\mathrm{T}_{2}$ weighted images $(5000 / 85)$, proton density weighted images (2500/20), and/or fluid attenuated inversion recovery (FLAIR) images. The examinations were evaluated for high signal changes in the white matter (white matter lesions, WML). The WML were counted and divided into two groups: 4-10 lesions were graded as moderate changes $(+)$ and 11-30 lesions as severe changes $(++)$. A cerebral infarct was diagnosed on the CT or MRI study if a cerebral tissue defect localised to a vascular territory was present. Cortical atrophy was diagnosed if the cerebral sulci were wider than $5 \mathrm{~mm}$. Atrophy was graded as moderate $(+)$ or severe $(++)$.

CONTROL GROUPS

In the studies of soluble CSF cytokines we used CSF from 23 otherwise healthy people with tension headaches. In the studies of NO metabolites in CSF we used as controls CSF from a different set of six healthy people with tension headaches. As controls for the in situ hybridisation studies of cytokine production in peripheral blood lymphocytes, we used bl prom healthy hospital staff matched for age and sex.

CAPILLARY ELECTROPHORESIS FOR NO

METABOLITES

Sample analysis for NO metabolites was performed by the capillary electrophoresis technique. ${ }^{21}$ Vials and equipment were rinsed in deionised, distilled water (Elgastat prima 1-3, Elga Bucks, UK). The samples were diluted 1:10, ultrafiltered at $5000 \mathrm{~g}$ through Ultrafree-MC filters (Millipore), and analysed on an HP 3D capillary electrophoresis system (Hewlett Packard, Waldbronn, Germany).

The electrolyte consisted of $25 \mathrm{mM}$ sodium sulphate containing 5\% NICE-Pak OF Anion-BT (osmotic flow modifier) in MilliQ + water. Samples were injected by electromigration for 20 seconds at $-6 \mathrm{kV}$ and analysed at a negative potential of $300 \mathrm{~V} / \mathrm{cm}$. Data were acquired at a response time of $0.1 \mathrm{~s}$ at $214 \mathrm{~nm}$ onto an HP 3D CE Chem Station data system. The samples were coded to the laboratory staff.

CYTOKINE IN SITU HYBRIDISATION

Peripheral blood mononuclear cells and CSF cells were isolated and dried onto slides. TNF $\alpha$, IFN $\gamma$, IL4, and IL10 mRNA expressing cells were detected by in situ hybridisation as previously described. ${ }^{22}$ Briefly, synthetic oligonucleotide probes 3-end labelled with $\left[{ }^{35}\right.$ S] deoxyadenosine-5- $\alpha$-(thio)-triphosphate (Dupont Scandinavia, Stockholm, Sweden) were used. A probe complementary to the antisense strand of the same base was included as a control. Hybridisation was performed for

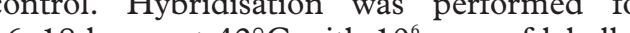
of labelled probe per $100 \mu \mathrm{l}$ of hybridisation mixture. After dried, and exposed for two weeks. Slides were then developed in Kodak D19 and stained. Coded slides were evaluated by light microscopy and cells with more than 14 autoradiographic silver grains were regarded as cytokine expressing. $^{22}$

CYTOKINE DETERMINATIONS IN CSF

IFN $\gamma$ levels were determined by ELISA. In brief, Maxisorp plates were coated overnight with antihuman IFN $\gamma$ (Kabi Diagnostica), 5 $\mu \mathrm{g} / \mathrm{ml}$, in bicarbonate buffer, pH 9.6. After

Table 4 Number of $m R N A$ expressing cells in peripheral blood in patients with neuropsychiatric lupus

a mononuclear cells. Median (interquartile range) is given

\begin{tabular}{llll}
\hline Cytokine $^{*}$ & NPLE & Controls & $p$ Valuet \\
\hline TNF $\alpha$ & $34(11-51)$ & $3(1-5)$ & $<0.004$ \\
IFN $\gamma$ & $9(4-12)$ & $2(0-2)$ & $<0.002$ \\
IL10 & $7(4-12)$ & $1(0-8)$ & $<0.003$ \\
IL4 & $4(2-7)$ & $1(0-2)$ & NS
\end{tabular}

${ }^{\mathrm{TNF}}=$ tumour necrosis factor; IFN $=$ interferon; $\mathrm{IL}=$

The Wilcoxon's rank sum test. 
washing and blocking with bovine serum albumin, samples and standards (recombinant human IFN $\gamma$; Genzyme Novakemi) were incubated for two hours at $37^{\circ} \mathrm{C}$. Plates were
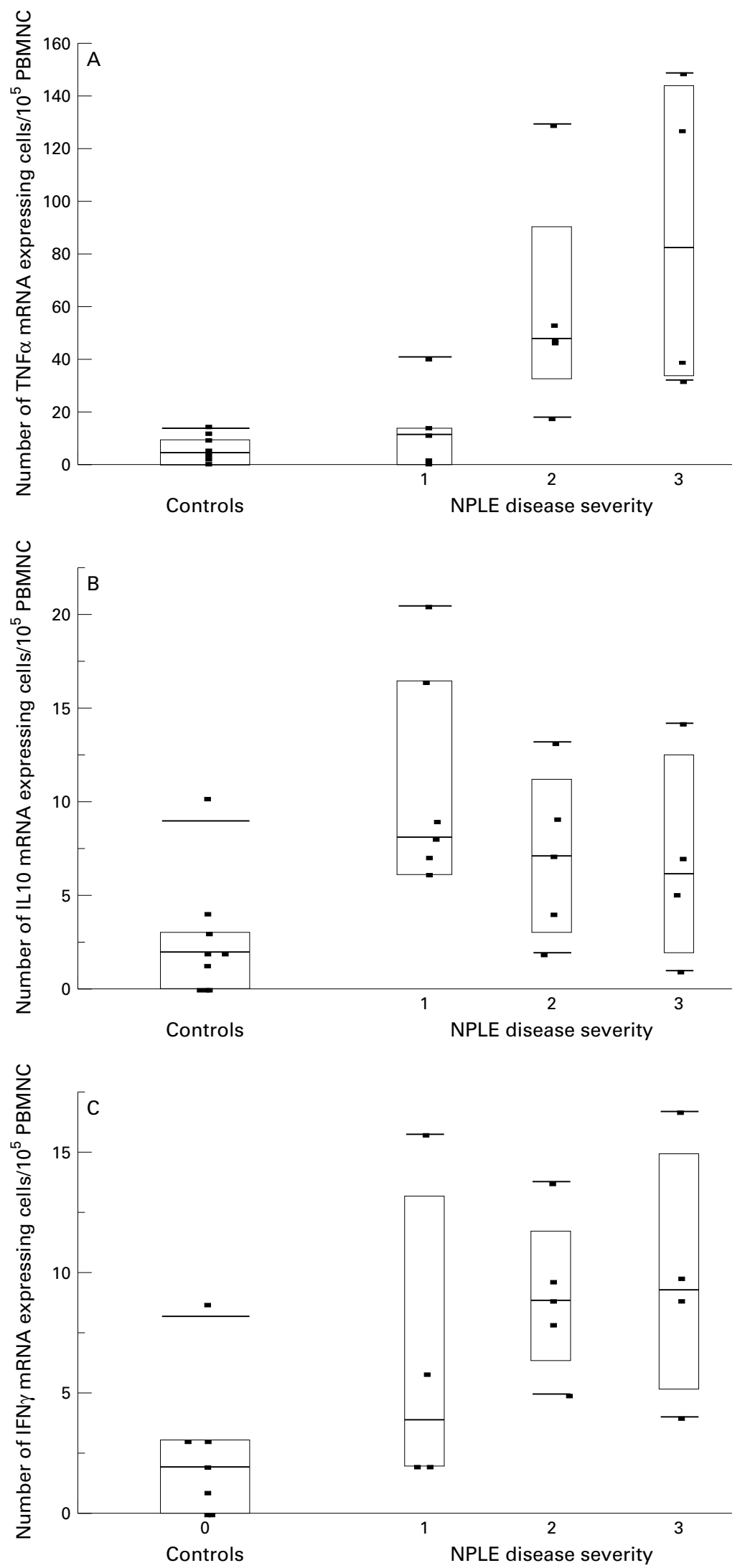

Figure 1 Box plot showing 10th, 25th, 50th, 75th, and 90th centile distribution of the number of peripheral blood cells (PBMNC) expressing $m R N A$ for (A) tumour necrosis factor a (TNFa), (B) interleukin 10 (IL10), and (C) interferon $\gamma($ (IFN $\gamma$ ) in 11 healthy
controls and 16 patients with mild (1), moderate (2), or severe (3) neuropsychiatric lupus disease had more $T N F$ expressing cells than controls; $p<0.001$ for both groups. washed and incubated with biotinylated antihuman IFN $\gamma$ (Kabi Diagnostica) followed by extra-avidin alkaline phosphatase and substrate. The colour developed with $p$-nitropheny at $405 \mathrm{~nm}$ in an ELISA plate reader and compared with known standards.

CSF TNF $\alpha$ was measured by ELISA on plates coated with monoclonal antibody to $\mathrm{TNF} \alpha$ (Endogen, MA) with recombinan human $\mathrm{TNF} \alpha$ (Endogen, MA) as standard and a second biotin labelled antihuman $\mathrm{TNF} \alpha$ monoclonal antibody (Endogen MA). A simiar ELISA assay was used to measure levels of IL4 and IL10, using monoclonal antibody L4-I (IL4-82, Mabtech), recombinant huma IL4, (Genzyme), and biotinylated monoclonal antibody IL4-II (IL4-12, Mabtech), monoclonal antibody IL10 (Pharmingen), recombinant human IL10 (R\&D), and biotin labelled antihuman IL10 monoclonal antibodies (Pharmingen), respectively.

IL6 activity in CSF diluted $1 / 50$ was measured by a proliferation assay using the IL6 dependent B9 murine cell line. After dilution, samples were inactivated by 30 minutes' incubation at $56^{\circ} \mathrm{C}$. Samples and standards (recombinant human IL6, Genzyme) were incubated for 72 hours at $37^{\circ} \mathrm{C}$. After the addithe cells were harvested and incorporation was measured with a $\beta$ counter.

ROUTINE CSF STUDIES

In CSF white blood cells were counted, the IgG index was obtained, albumin fractions were calculated, and isoelectric focusing was performed to detect oligoclonal bands. ${ }^{23}$

TATISTICAL ANALYSIS

The Wilcoxon non-parametric rank sum test, Fisher's exact test, and linear correlation were calculated using "JMP" software ( SAS Institute Inc, Carey, North Carolina). A p value $<0.05$ was considered significant.

Results

CLINICAL AND LABORATORY DATA

Table 1 lists the clinical and laboratory data of the 30 patients with NPLE. Twelve patient were classified as having mild, 11 as having moderate, and seven as having severe NPLE. SLEDAI scores ranged from 0 to 26 with a SLEDI scores ranged from 0 to 26 with a were analysed separately for neuropsychiatric and non-neuropsychiatric items, it was noted that the overall SLEDAI scores represented, to a large extent, neuropsychiatric rather than non-neuropsychiatric types of disease activity (table 2). At the time of inclusion 19/30 patients were being treated with prednisone, with doses ranging from 3.75 to $40 \mathrm{mg} /$ day. Eleven of 30 patients had detectable anti-dsDNA antibodies and 23/30 had antiphospholipid antibodies (positive test for anticardiolipin antibodies (IgG or IgM) or positive lupus anticoagulant test). Six of 21 patients had a moderately raised CSF albumin fraction, indicating some degree of blood-brain barrier damage. Pleiocytosis of clinical significance 

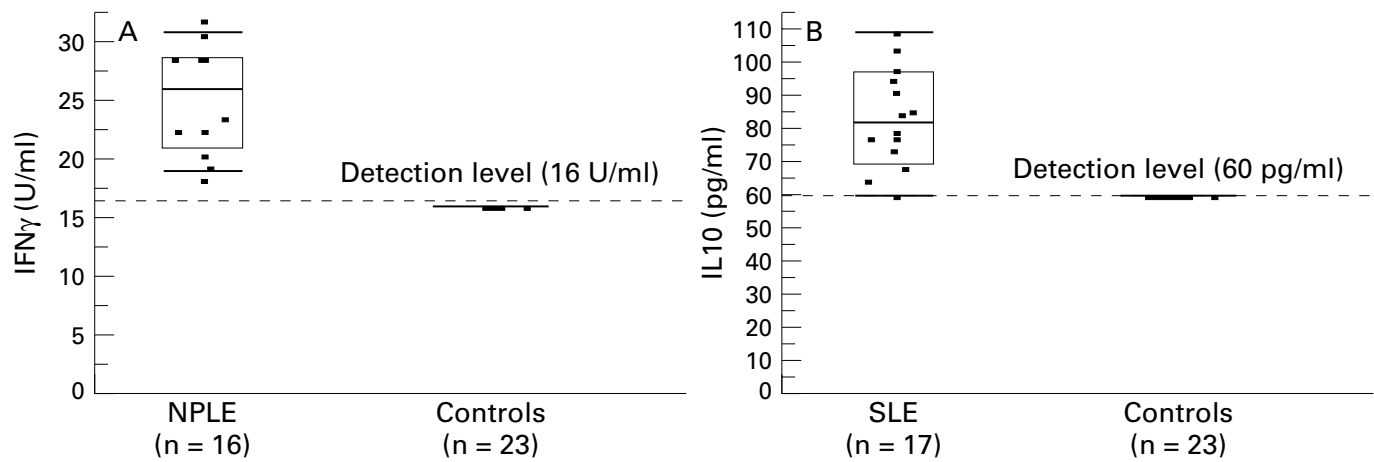

Figure 2 Box plot showing 10th, 25th, 50th, 75th, and 90th centiles for (A) soluble interferon $\gamma$ (IFN $\gamma$ ) and (B) soluble interleukin 10 (IL10) in the cerebrospinal fluid of 16 patients with neuropsychiatric lupus and 23 healthy controls who all
had levels under the detection level (dashed line). Patients $v$ controls: IFN $p<0.001 ;$ IL 10, $p<0.0001$ by Fisher's exact test evaluated at detection level.

was not present in any patient. Five patients had oligoclonal bands. The IgG index was slightly raised in one patient. Table 3 provides a retrospective classification of the patients according to the ACR case definitions for neuropsychiatric syndromes seen in SLE.

MRI INVESTIGATIONS

Thirteen of 28 patients had normal findings on MRI. In the two patients examined by CT one had a normal study and the other had cortical atrophy. Cerebral infarct was present in six and cortical atrophy in eight of the 30 patients. WML were seen in 12 patients and located in the periventricular white matter, the deep white matter and, often, in the subcortical white matter without any specific pattern. Two patients (Nos 8 and 27) had WML preferentially in the periventricular white matter. Five tially in the periventricular white matter. Five patients had supratentorial infarcts affecting the cortex or a deeper situated vascular territory. One patient (No 2) had three small lacunar infarcts in the pons as well as a subarachnoid haemo terns. Selective cerebral angiography did not disclose any aneurysm in this patient.

Table 1 presents the MRI findings.

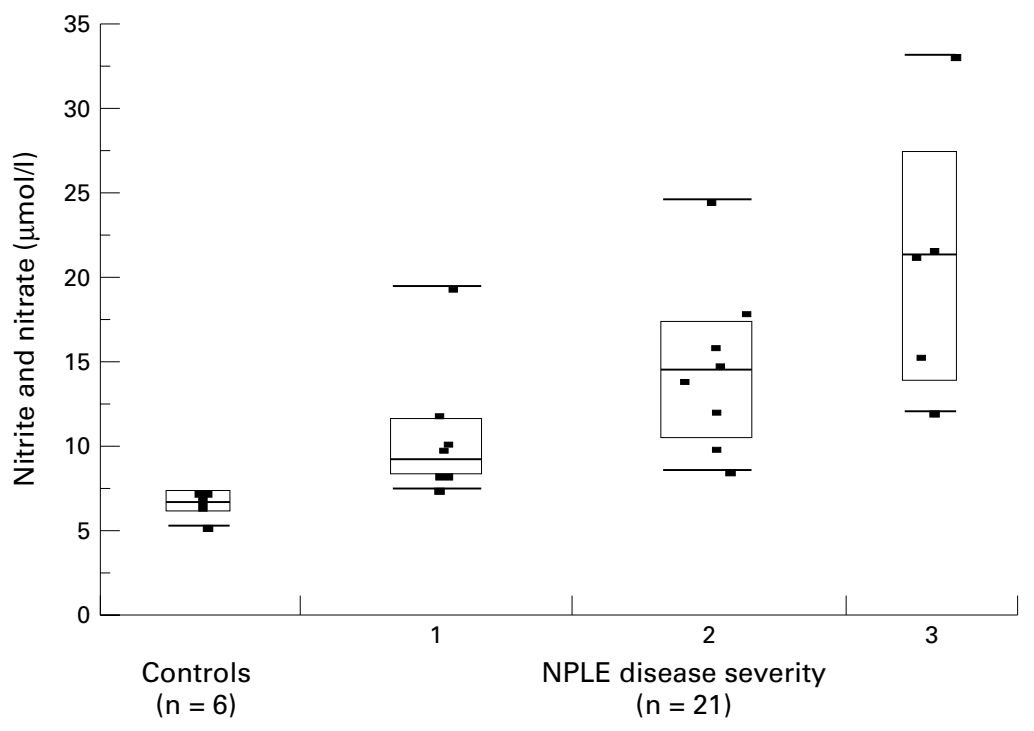

Figure 3 Box plot showing 10th, 25th, 50th, 75th, and 90th centiles of cerebrospinal fluid concentration of nitric oxide oxidation products nitrite and nitrate in six healthy controls and 21 patients with mild (1), moderate (2), or severe (3) neuropsychiatric hipus. $p<0.004$ significantly from the group with severe disease $(p<0.04)$.
NUMBER OF CYTOKINE EXPRESSING CELLS

Patients with SLE had significantly more peripheral blood lymphocytes containing mRNA for TNF $\alpha$, IFN $\gamma$, and IL10 than age and sex matched controls (table 4). There was a positive correlation between the number of TNF $\alpha$ mRNA expressing cells and neurological disease severity (fig 1A) and, also, a correlation of borderline significance with the neurological items of the SLEDAI $(p=0.057)$. In contrast there was no correlation between $\mathrm{TNF} \alpha$ mRNA expressing cells and total SLEDAI score. Furthermore, there was no SLEDAI score. Furthermore, there was no che expressing cells and disease severity (figs $1 \mathrm{~B}$ and $\mathrm{C}$ ). We could not detect mRNA for IFN $\gamma$, TNFa, IL4, or IL10 in circulating CSF ymphocytes. Of note, none of these patients had CSF pleiocytosis at the time of this study.

OLUBLE CYTOKINE LEVELS

ncreased levels of IFN $\gamma$ and IL10 were found in the CSF of patients with NPLE compared with controls (figs $2 \mathrm{~A}$ and $\mathrm{B}$ ). Thus the IFN concentration in patients with SLE was 24.7

4.3) $\mathrm{U} / \mathrm{ml}$, whereas controls all had values below the detection level of $16 \mathrm{U} / \mathrm{ml}$. CSF IL10 for patients with NPLE was $84.2(16.6) \mathrm{pg} / \mathrm{ml}$ controls all had values below the detection level of $60 \mathrm{pg} / \mathrm{ml}$. CSF levels of soluble TNF $\alpha$, IL4, and IL6 did not differ significantly between patients and controls (data not shown). There were no correlations between soluble cytokine levels and NPLE severity or SLE activity as measured with SLEDAI.

NO METABOLITES

Patients with NPLE had increased levels of NO metabolites (the sum of the two metabolite nitrite and nitrate) in the CSF compared with controls (14.9 (7.3) $\quad v \quad 6.6 \quad(0.8) \quad \mu \mathrm{mol} / 1$, $\mathrm{p}<0.0003)$. The concentrations of CSF nitrite and nitrate values correlated with NPLE severity as determined by the doctor's global assessment. There was a significant difference in NO metabolites between each of the three severity subgroups and controls $(p<0.004$ for al groups). Also, the group with mild CNS disease differed significantly from the group with severe disease $(p<0.04)$ (fig 3 ). Moreover, in the patients who underwent both investigations there was a strong positive correlation 
$\left(r^{2}=0.69, p=0.007\right)$ between the number of TNF $\alpha$ mRNA expressing cells in peripheral blood and the level of NO metabolites in the CSF. Steroid dose, immunosuppressive drugs, and SLEDAI scores did not correlate with the CSF NO metabolites (data not shown).

Discussion

To our knowledge this is the first study to investigate inflammatory mediators in patients with NPLE in conjunction with markers of NO metabolites. Despite the fact that none of our patients had CSF pleiocytosis we found that most patients with NPLE had evidence for enhanced immunological and inflammatory enhanced immunological and inflammatory
activity in both the intrathecal and systemic compartment. We extend our previous report that patients with NPLE have increased levels of CSF NO oxidation products and show that these patients also have high numbers of TNF $\alpha$, IFN $\gamma$, and IL10 mRNA expressing cells in the peripheral blood.

A new finding in this study is the observation that patients with NPLE not only have high levels of CSF NO metabolites and increased numbers of TNF $\alpha$ producing peripheral lymphocytes but also that there is a correlation between the number of TNF $\alpha$ mRNA expressing cells, CSF NO metabolites, and severity of NPLE symptoms, suggesting that TNF $\alpha$ may be of pathogenic importance in NPLE. Previous studies of the role of TNF $\alpha$ in the pathogenesis of SLE are conflicting. In mouse models as well as in human studies this cytokine has been assigned both an inductive and a protective role. ${ }^{24}$ There are reports of increased local production of $\mathrm{TNF} \alpha$ at sites of SLE inflammatory activity, as in active lupus nephritis where mesangial cells have been shown to produce TNFa. ${ }^{25}$ However, in accordance with our results, circulating levels of $\mathrm{TNF} \alpha$ do not differ between patients with SLE and controls in most studies. ${ }^{26}{ }^{27}$ Moreover, measurements of free circulating $\mathrm{TNF} \alpha$ may be misleading because $\mathrm{TNF} \alpha$ molecules are usually bound to circulating soluble $\mathrm{TNF} \alpha$ receptors. Such soluble receptors have been shown to occur in abundance in patients with SLE and their levels were shown to correlate with disease activity. ${ }^{28} 29$ Thus it may be more meaningful to measure cellular production of this particular cytokine. Our results using this measurement suggest that increased systemic $\mathrm{TNF} \alpha$ production may be related to increased intrathecal production of $\mathrm{NO}$ and, indirectly, with NPLE activity. An important question is whether the finding of increased TNF $\alpha$ expression in active NPLE can be the result of confounding, due to the simultaneous presence of active non-neuropsychiatric (systemic) SLE activity and neurological symptoms that are hard to characterise-for example, tension headaches. However, the finding that the patients in this study as a group had limited non-neuropsychiatric disease activity, and yet showed increased TNF expression that correlated with the severity of neuropsychiatric disease, suggests that this was not the case. It may be of interest in future studies to include patients without SLE but with active diseases known to be associated with increased expression of $\mathrm{TNF} \alpha$, such as rheumatoid arthritis or inflammatory bowel disease.

Another important question is whether inflammation in NPLE is intrathecal or systemic. The CSF cell numbers in our patients were low and we could not detect mRNA were low and we could not detect mRNA expression for production of any of the investigated cytokines ( $\mathrm{TNF} \alpha, \mathrm{IFN} \gamma, \mathrm{IL} 10$, or IL4) in
$\mathrm{CSF}$ lymphocytes. These findings differ from previous studies of patients with multiple sclerosis, where increased numbers of IFN $\gamma$ and L10 producing cells were found using the g the we technique as here. ${ }^{30}$ In the six patients with abnormal albumin fractions, this abnormality did not correlate with CSF cytokine levels. This finding argues against the possibility that either passive diffusion or passage over a damaged blood-brain barrier is the cause of high intrathecal cytokine levels. Thus our results raise the possibility that peripheral pyeral inflammatory mediators such as TNF $\alpha$ induce intrathecal inflammation.

In a few earlier investigations cytokines were reported to be present in the CSF in acute cases of cerebral SLE. Thus Hirohata and Miyamoto reported increases of IL6. ${ }^{14}$ AlcocerVarela et al found increases in both IL 6 and IL 1 activity, ${ }^{13}$ and Shiozawa et al showed increased evels of IFN $\gamma$ in lupus psychoses. ${ }^{15}$ In our patients we did not find general increases of IL6. This may be accounted for by the more chronic presentation in our patients. It may be of relevance that one of our patients, who had acute psychosis, did have CSF IL6 in the same increased range as that reported by other groups.

Both an increased number of peripheral blood mononuclear cells producing IL10 and high systemic levels of IL10 which correlate with SLE disease activity indices have been described in several previous studies of patients with SLE. ${ }^{31}{ }^{32}$ In agreement with these studies we found that our patients had an increased umber of IL 10 producing cells in peripheral lood. We also found that patients with NPLE had high levels of intrathecal IL10. To our knowledge there are no previous reports on intrathecal IL10 in patients with SLE. Whether this is yet another manifestation of constitutionally high IL10 production or a specific marker for neuropsychiatric disease in SLE needs to be considered in future studies.

Previously, Ohga et al described high levels of CSF IFN $\gamma$ and TNF $\alpha$ in a single case of active upus meningoencephalitis where the CSF cytokine levels declined as symptoms subsided. ${ }^{33}$ Al-Janadi et al have previously reported high systemic levels of IFN $\gamma$ in patients with SLE, including 10 patients with severe NPLE ${ }^{34}$ In 10 patients with NPLE have increased IFN $\gamma$ activity in both peripheral blood and CSF. IFN $\gamma$ can induce the synthesis of NO by astrocytes. ${ }^{35}$ Thus IFN $\gamma$ produced intrathecally may trigger expression of iNOS and increase NO production in the central nervous system, which over time may cause toxic damage to neural tissue. A causal relation of this kind was shown in 
injection caused systemic inflammation and induced iNOS expression in the brain. ${ }^{3}$ Therefore, it was of interest to measure NO metabolites directly.

The level of NO metabolites in the CSF of our patients was raised and was found to correlate with neuropsychiatric disease severity. Thus CSF NO metabolites may serve as a marker for NPLE and, possibly, as a tool to monitor treatment effects. It is especially interesting that some patients with only subjective and mild symptoms of NPLE have significantly raised levels of NO metabolites in the CSF. Previously it has been shown that patients with SLE with pulmonary symptoms have increased levels of NO in expired air. ${ }^{37}$ There is also a report of systemically high levels of NO metabolites in patients with SLE, which correlated with disease activity. ${ }^{38}$ However, measurements of systemic NO levels are difficult to interpret because they are influenced by dietary factors. ${ }^{21} \mathrm{NO}$ in the CSF may also have pathophysiological significance in that some NO metabolites are extremely toxic and can cause tissue damage, ${ }^{18}$ which in turn may be the direct cause of diffuse symptoms in NPLE.

MRI findings in this study are in agreement with previous studies ${ }^{39}$ on patients with NPLE. A majority of the patients had MRI changes such as WML, atrophy, and cerebral infarctions. However, there was no correlation between any of these findings and NPLE severity, cytokines, or CSF NO levels.

A major limitation in this study is the lack of a control group of patients with active SLE without neuropsychiatric disease. However, it should be noted that our group of patients as a whole had relatively little non-neuropsychiatric SLE activity (table 2), making it less likely that the finding of increased cytokine expression and NO metabolites could be explained by the non-neuropsychiatric disease activity. Another interesting control group would be patients without SLE but with otherwise comparable neurological or psychiatric disease. Although the relations between disease activity, cytokine expression, and NO metabolites in this study are suggestive, they cannot by themselves prove causality. The overall findings in this paper suggest that better understanding of the relations between cytokines, inflammatory mediators, and disease activity may have both diagnostic and therapeutic implications. Thus measurement of NO metabolites in the CSF might support the diagnosis of NPLE and specifically guide treatment towards antiinflammatory therapies. The use of more specific inhibitors of NO production might be evaluated in this context. "Biological" antagonists of TNF and other cytokines could also be evaluated with respect to SLE, though the precise role of each cytokine in SLE would have to be scrutinised further before any therapeutic trials could be undertaken.

In summary, in patients with NPLE, we found correlations between systemic $\mathrm{TNF} \alpha$ production, intrathecal NO metabolite levels, and severity of neuropsychiatric symptoms.
This supports our hypothesis that inflammatory mediators are important in the pathogenesis of NPLE and that these substances are candidate targets for future treatment. This study was supported by the Swedish Rheumatism Associa-
tion, King Gustaf V 80-years Foundation, Karolinska Institute
research Foundation, and Research Foundation Margareta.

1 Pistiner M, Wallace DJ, Nessim S, Metzger AL, Klinenberg

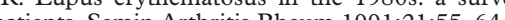
2 West SG. Neuropsychiatric lupus. Rheum Dis Clin North Am 1994;20:129-58.

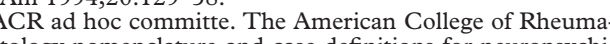
tology nomenclature and case definitions for neuropsych-
atric lupus syndromes. Arthritis Rheum 1999;42:1-35.

Denburg S, Behmann S, Carbotte R, Denbur J. Lymphocyte antigens in 5 Bonfa, Golombek S, Kaufman LD, Skelly S, Weissbach H, Brot $\mathrm{N}$, et al. Association between lupus psychosis and
anti-ribosomal $\mathrm{P}$ protein antibodies. N Engl J Med 1987:317:265-71

6 Toubi E, Khamashta M, Panarra A, Hughes G. Association of antiphospholipid antibodies with central nervous system 99:397-401.
.

7 West SG, Woodruff E, Wener MH, Kotzin BL. Neuropsychiatric lupus erythematosus: a 10-year prospective study
on the value of diagnostic tests. Am J Med 1995;99:15363

8 Ramos PC, Mendez MJ, Ames PRI, Khamashta MA Hughes GRV. Pulse cyclophosphamide in the treatment Rheumatol 1996;14:295-9.

9 Alosachie IJ, Terryberry JW, Mevorach D, Chapman Y, Lorber M, Torre D, et al. Central nervous system (CNS)

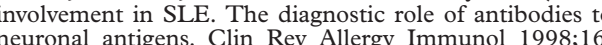
275-84.

Chapman J, Cohen-Armon M, Shoenfeld Y, Korczyn AD

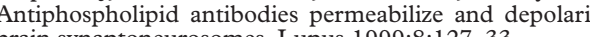

1 Arditi M, Manogue KR, Caplan M, Yogev R. Cerebrospin fluid cachectin/tumor necrosis factor-alpha and platele activating factor concentrations and severity of bacter 2 Olsson T. Tytokines in multiple sclerosis and its experimental models. In: Londei $M$, ed. T cell autoimmunity and mutiple sclerosis. Texas, USA. Landes Bioscience, Interleukin-1 and interleukin- 6 are increased in the cerebrospinal fluid of patients with CNS lupus erythematoLupus 1992:1:111-17. 4 Hirohata S, Mivamoto T. Elevated levels of interleukin-6 in cerebrospinal fluid from patients with systemic lupus

15 Shiozawa S, Kuroki Y, Kim M, Hirohata S, Ogino Interferon-alpha in lupus psychosis. Arthritis Rheum 199

6 Brundin L, Svenungsson E, Morcos E, Andersson M, oxide formation in cerebral systemic lupus erythematosus.

Ann NC, Dickson DW, Liu W, Brosnan CF. Induction nitric oxide synthase activity in human astrocytes by interleukin- 1 beta and interferon-gamma. J Neuroimmun

Brosnan C, Battistini L, Raine CS, Dickson DW, Casadevall A, Lee SC. Reactive nitrogen intermediates in human
neuropathology: an overview. Dev Neurosci 1994;16:152-

Tan EM, Cohen AS, Fries JF, Masi AT, McShane DJ, Rothfield NF, et al. The 1982 revised criteria for classification of 20 Bo

, Growitz M, Caron D, Chang C, Committee on Progress studies in SLE. oncada S. A rapid and high performance capillary electrophoresis. Biochem Biophys Res Commun 1994;200:951-7.
2 Link J, Söderström M, Olsson T, Höjeberg B, Ljungdahl $\AA$,
Link H. Increased transforming growth factor- $\beta$, interleukin-4 and interferon- $\gamma$ in multiple sclerosis. Ann Neurol 1994;36:379-86.
Hansson LO, Link H, Sandlund L, Einarsson R. Oligoclonal Hansson LO, Link H, Sandlund L, Einarsson R. Oligoclonal
IgG in cerebrospinal fluid detected by isoelectric focusing m. Scand J Clin Lab Invest 1993;53:48724 Jacob C. Tumor necrosis factor $\alpha$ in autoimmunity: pretty 5 Malide D Russo P, Bendayan M. Presence of tu sis factor alpha and interleukin- 6 in renal mesangial cells of lupus nephritis patients. Hum Pathol 1995;26:558-64. SH. Cytokine concentration in serum of lupus erythematosus patients: the effect on acute phase response. J Me 1997 
27 Maury CPJ, Teppo A-M. Tumor necrosis factor in the serum of patients with systemic
Arthritis Rheum 1989;32:146-50

28 Aderka D, Wysenteck A, Engeta. F, Molad Y, et al. Correlation between serum levels of soluble tumor necrosis factor receptor and disease activity in
systemic lupus erythematosus. Arthritis Rheum 1993;36:

29 Heilig B, Fiehn C, Brockhaus M, Gallati H, Pezzutto A, Hunstein W. Evaluation of soluble tumor necrosis factor (TNF) receptors and TNF receptor antibodies in patients with systemic lupus erythematosus, progressive systemic
sclerosis, and mixed connective tissue disease. J Clin Immunol 1993;13:321-8. Cytokine profile in interferon- $\beta$ treated multiple sclero Patints. reduction of finterleuke 10 mRNA expressin cells in: peripher

interleukin-6 in lup, Mackiewics SH. Interleukin-10 and arthritis, correlation with acute phase proteins. Clin Rheumatol 1997;16:275-8.

Y, Fior R, Alcocer-Varela J, Wijdenes J, Fourrier B, et al. In vivo production of
interleukin-10 by non-T cells in rheumatoid arthritis, Siögren's syndrome, and systemic
Arthritis Rheum 1994;37:1647-55.

33 Ohga S, Gondo K, Nomura A, Onoe Y, Matsuzaki A, Hara profiles in central nervous system infections. Br J RheumaAl-Janadi M, Al-Balla $S$, Al A, Raziuddin S. Cytokine profile in systemic lupus erythematosus, rheuma-
toid arthritis, and other rheumatic diseases. J Clin Immunol 1993;13:58-67.
5 Lee SC, Dickson DW, Liu W, Brosnan CF. Induction of nitric oxide synthase activity in human androcytes by
interleukin-1 beta and interferon-gamma. J Neuroimmunol 1993;46:19-24.

6 Wong M-L, Rettori V, Al-Shekhlee A, Bongiorno P, Canteros G, McCann SM, et al. Inducible nitric oxide syn-
thase gene expression in the brain during systemic inflammation. Nat Med 1996;2:581-4.

7 Rolla G, Brussino L, Bertero MT, Colagrande P, Converso $\mathrm{M}$, Bucca C, et al. Increased nitric oxide in exhaled air of 1997;24:1066-71.
Gilkeson G, Cannon C, Oates J, Reilly C, Goldman D, Petri 8 Gilkeson G, Cannon C, Oates J, Reilly C, Goldman D, Petri
$\mathrm{M}$. Correlation of serum measures of nitric oxide production with lupus disease activity. J Rheumatol 1999;26:318-27.

Chinn RJS, Wilkinson ID, Hall-Craggs MA, Paley NJ, Shoron spectroscopy in Magnetic resonance and cerebral prtosus. Arthritis Rheum 1997;40:36-46.
tos 